\title{
3.6 Fitness, Fatness and Exercise Blood Pressure in Adolescence
}

\author{
Zhengzheng Huang ${ }^{1,2, *}$, Chloe Park ${ }^{3}$, Nishi Chaturvedi', Laura Howe ${ }^{4}$, James Sharman ${ }^{2}$, Alun Hughes ${ }^{3}$, Martin Schultz ${ }^{2}$ \\ ${ }^{1}$ Menzies Institute for Medical Research, Tasmania, Australia \\ ${ }^{2}$ University of Tasmania, Hobart, Australia \\ ${ }^{3}$ University College London, London, UK \\ ${ }^{4}$ University of Bristol, Bristol, UK
}

\section{ABSTRACT}

Objective: Exaggerated exercise blood pressure (BP) is associated with cardiovascular risk factors in adolescence. Aerobic fitness and adiposity (fat mass or 'fatness') are important independent contributors to cardiovascular risk in adolescence, but their interrelated associations with exercise BP are unknown. The aim of this study was to determine the respective relationship between fitness, fatness and exercise BP in a large birth cohort of adolescents.

Methods: 2356 adolescents from the Avon Longitudinal Study of Parents and Children (aged 17.8 \pm 0.4 years, 38.5\% male) completed a submaximal exercise step-test that allowed fitness $\left(\mathrm{VO}_{2 \max }\right)$ to be determined from workload and heart rate using a validated equation. Exercise BP was measured immediately on test cessation and fatness calculated as the ratio of total fat mass to total body mass measured by DXA.

Results: Exercise systolic BP decreased stepwise with each tertile of fitness (146 [144, 147]; 142 [141, 144]; 141 [139, 142] mmHg), but increased with each tertile of fatness $(137$ [135, 138]; 143 [142, 144]; 148 [147, 149] mmHg). In separate models, fitness and fatness were independently associated with exercise systolic BP after adjustment for sex, age, height, smoking and socioeconomic status (standardised $\beta$ : $-1.97,95 \% \mathrm{CI}:-2.90,-1.04 \mathrm{mmHg} / \mathrm{SD}$ and $5.69,95 \% \mathrm{CI}: 4.61,6.77 \mathrm{mmHg} / \mathrm{SD} \mathrm{respectively}$ ). However, when fitness and fatness were included in the same model, only fatness remained independently associated with exercise BP $(6.15,95 \%$ CI: 4.88, $7.41 \mathrm{mmHg} / \mathrm{SD})$.

Conclusion: Both fitness and fatness are associated with exercise BP in adolescence. However, the fitness-exercise BP association was not independent of fatness, suggesting fatness accounts for the association with exercise BP.

(C) 2019 Association for Research into Arterial Structure and Physiology. Publishing services by Atlantis Press International B.V. This is an open access article distributed under the CC BY-NC 4.0 license (http://creativecommons.org/licenses/by-nc/4.0/). 